\title{
Tuberculous pericarditis associated with hoarseness of voice due to left recurrent laryngeal nerve paralysis
}

\author{
Ragai Fouda, ${ }^{1}$ Hussam Ammar, ${ }^{2}$ Ramy Edward, ${ }^{3}$ Waleed M Alnabawy, ${ }^{4}$ Iman M Fouda ${ }^{5}$
}

${ }^{1}$ Department of Internal Medicine, Kasr Elaini Hosp-Cairo University, Cairo, Egypt;

${ }^{2}$ Department of Internal Medicine, University of Texas Health Science Center at Houston, Houston, Texas, United States;

${ }^{3}$ Department of Radiology, Kasr Elaini Hosp-Cairo university, Cairo, Egypt;

${ }^{4}$ Department of Internal Medicine, Beny Suef University, Beny Suef, Egypt;

${ }^{5}$ Department of Internal Medicine, National research centre, Cairo, Egypt

Correspondence to Dr Hussam Ammar, h ammar70@yahoo.com

\section{Summary}

A 16-years-old Egyptian girl presented with massive pericardial effusion, fever, weight loss and hoarseness of voice. Laryngoscopy showed left vocal cord paralysis. Chest CT revealed pericardial effusion, amalgamated mediastinal lymph nodes and clear lung fields. Pericardial fluid analysis revealed a lymphocytic exudate with high adenosine deaminase enzyme level, negative stains and cultures for bacteria and fungi. Despite a negative nucleic acid test for tuberculosis; antituberculous and corticosteroids therapies resulted in resolution of pericardial effusion after 3 weeks but hoarseness of voice persisted. Few cases of vocal cord paralysis with tuberculous mediastinal lymphadenopathy were reported in English literature.

\section{BACKGROUND}

Tuberculous pericarditis is a rare cause of pericardial effusion in developed countries, while it is the cause of up to $70 \%$ of cases in developing countries. Despite that almost all cases of tuberculous pericarditis are associated with mediastinal lymphadenopathy, only few cases of left vocal cord paralysis with tuberculous mediastinal lymphadenopathy were reported in English literature.

\section{CASE PRESENTATION}

A 16-year-old Egyptian girl had fatigue and shortness of breath for the last 6 months. A blood count revealed microcytic anaemia with a haemoglobin $(\mathrm{Hb})$ of 7.6 grams/ dl. She was treated with ferrous sulphate tablets. Three months later, she complained of fever, night sweats, bony aches and hoarseness of voice. She lost 23 kilograms over the last year. A large pericardial effusion was found during an investigation done at another facility; the patient was referred to this hospital for further management. On physical examination; she was cachectic with a body mass index of 16 . Blood pressure was $130 / 80 \mathrm{~mm} \mathrm{Hg}$, pulse rate of $120 / \mathrm{min}$, temperature of $37.4^{\circ} \mathrm{C}$ and respiratory rate of $20 / \mathrm{min}$. The jugular venous pressure was elevated and there were bilateral firm non-tender upper deep cervical lymph nodes.

\section{INVESTIGATIONS}

A flexible direct laryngoscopy revealed normal appearance of vocal cords without any lesions or inflammation, but markedly diminished adduction and abduction of the left vocal cord diagnosing left vocal cord paralysis.

The $\mathrm{Hb}$ was 7.6 grams/dl, white blood cell count was $6400 / \mathrm{cmm}$ and platelet count was $719000 / \mathrm{cmm}$. The erythrocyte sedimentation rate (ESR) was $150 \mathrm{~mm} / \mathrm{h}$. Chest radiograph revealed cardiomegaly. Electrocardiogram showed sinus tachycardia, and low voltage. Chest CT (figures 1 and 2) revealed large pericardial effusion, clear lung fields and amalgamated mediastinal lymph nodes showing areas of break down. Transthoracic echocardiography (TTE) revealed large pericardial effusion, fibrinous strands in the pericardial cavity (figure 3) and right ventricular diastolic collapse. A 600 millilitres of amber coloured pericardial fluid was drained $(2520$ cells/cmm, mostly lymphocytes, protein $6.4 \mathrm{~g} / \mathrm{dl}$ and lactate dehydrogenase 627$)$. Bacterial

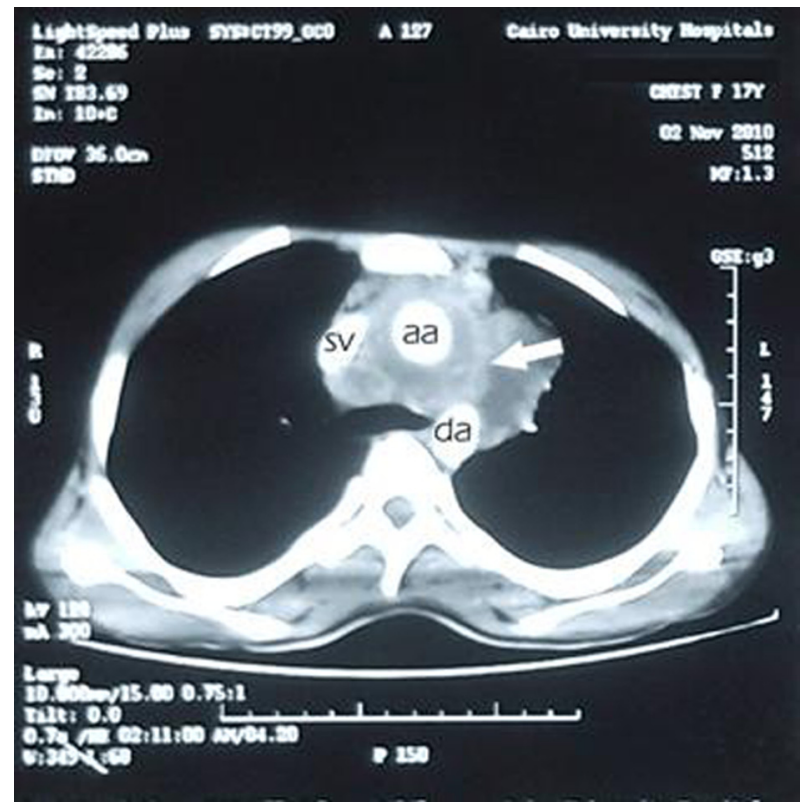

Figure 1 Postcontrast CT scan of the chest at the level of the aorto-pulmonary window. Caseating aorto-pulmonary (block arrow) lymph nodes forming a bulky nodal amalgum. aa, ascending aorta; da, descending aorta; sv, superior vena cava. 


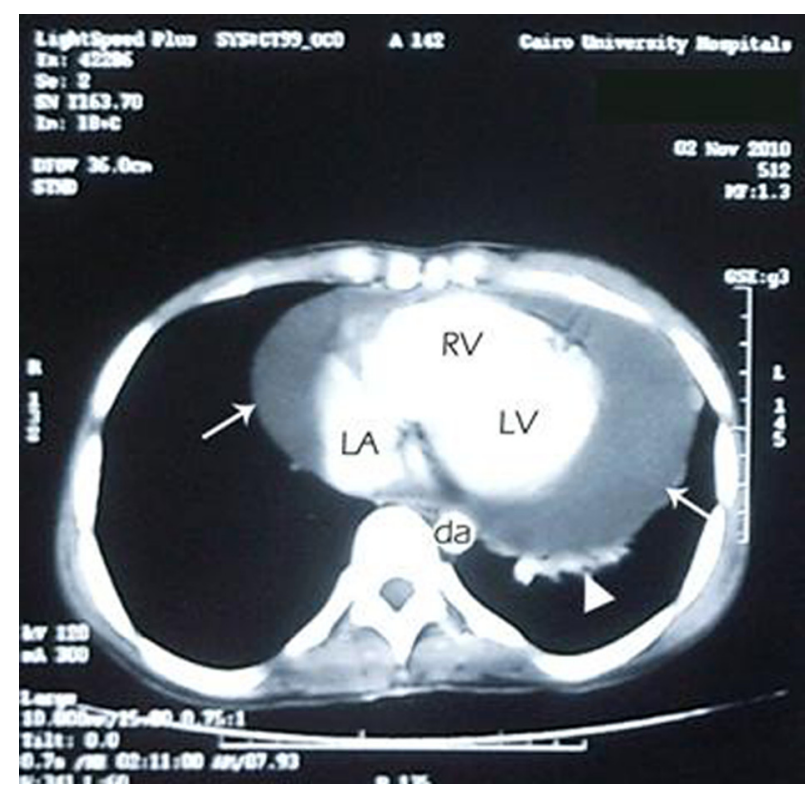

Figure 2 Postcontrast CT scan of the chest at the level of the cardiac chambers. Massive pericardial effusion (arrows) with associated atelectatic changes of the lingula (arrowheads). da, descending aorta; $L A$, left atrium; $L V$, left ventricle; $R V$, right ventricle.

and fungal cultures were negative. Acid fast bacilli and fungal stains were also negative. Adenosine deaminase in the pericardial fluid was high 61.8. The fluid cytology was negative for cancer cells.

\section{DIFFERENTIAL DIAGNOSIS}

- Tuberculous pericardial effusion

- Purulent pericardial effusion

- Malignant pericardial effusion.

\section{TREATMENT}

A presumptive diagnosis of probable tuberculous pericarditis was made. Treatment with rifampicin, isoniazid, ethambutol and pyrazynamide according to body weight was started in addition to $30 \mathrm{mg}$ of prednisone.

\section{OUTCOME AND FOLLOW-UP}

After 3 weeks, she improved dramatically, her appetite improved, and she gained 4 kilograms. The ESR decrease to $30 \mathrm{~mm} / \mathrm{h}$, the $\mathrm{Hb}$ increased to 12 grams/dl and repeated TTE showed complete resolution of pericardial effusion. The patient continued to have hoarseness of voice.

After 6 months of antituberculous therapy, she has no recurrence of pericardial effusion but she continued to have hoarseness of voice despite speech therapy. She did not decide regarding doing reconstructive vocal cord surgery yet.

\section{DISCUSSION}

Tuberculosis causes $70 \%$ of cases of large pericardial effusion and most cases of constrictive pericarditis in

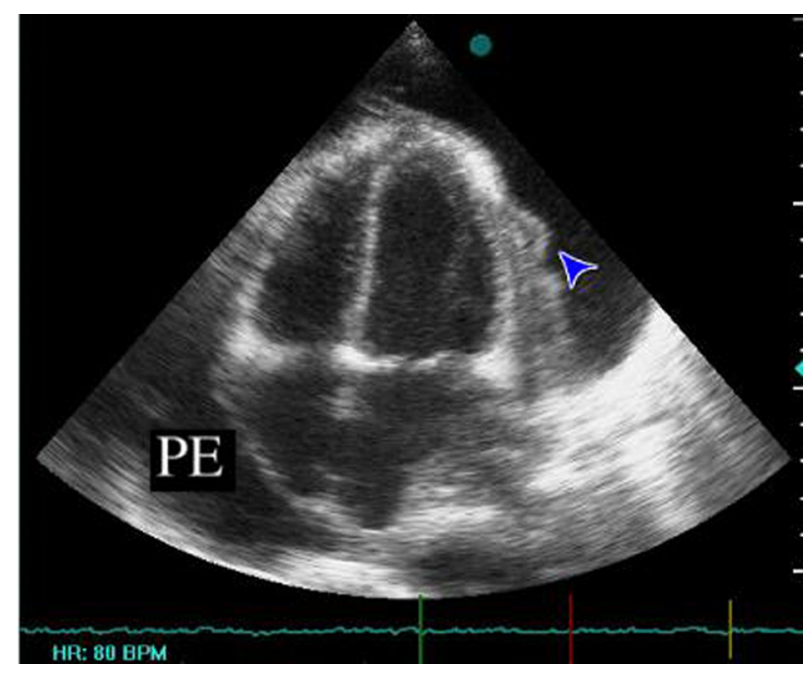

Figure 3 Apical four chambers transthroacic echocardiographic view shows global pericardial effusion (PE) and pericardial adhesions (arrow head).

developing countries, while it accounts for only $4 \%$ of cases of pericardial effusion and a smaller proportion of constrictive pericarditis cases in developed countries. Tuberculous pericarditis is a dangerous disease with a mortality of $17 \%$ to $40 \%{ }^{1}$

Tubercle bacilli reach the pericardium from the adjacent tracheobronchial lymph nodes either directly or via lymphatic channels. Less commonly seedling of the pericardium occurs with milliary tuberculosis and rarely mycobacteria spread directly from pleura or adjacent rib. ${ }^{2}$

The pericardium drains its lymphatic drainage to the anterior and posterior mediastinal lymph nodes and tracheobronchial lymph nodes. These lymph nodes are the ones involved in tuberculous pericarditis. The hilar lymph nodes are the least to be involved. These enlarged lymph nodes are not seen on chest radiographs but on chest CT they are seen in $100 \%$ of cases with caseation and amalgamation (as seen in our case) in more than half of the cases, in addition to a thickened, irregular, non-calcified pericardium with or without pericardial effusion. $^{3}$

Echocardiography is the test of choice for diagnosing pericardial effusion and tamponade. Fibrinous strands from the visceral pericardium and pericardial thickening are typical but not specific for tuberculous pericarditis. It is also used to guide needle pericardiocentesis. ${ }^{4}$

Left recurrent laryngeal nerve has a unique anatomical location in the aorto- pulmonary window where enlarged tuberculous mediastinal lymph nodes and inflammatory swelling can cause traction and compression on that nerve.

Despite that recurrent laryngeal nerve paralysis is extremely rare in those with tuberculous mediastinal lymphadenopathy, with few cases reported in English literature. ${ }^{5}$ We report a rare case of massive tuberculous pericardial effusion associated with mediastinal lymphadenopathy and left recurrent laryngeal nerve paralysis. 


\section{Learning points}

- Tuberculous pericarditis is a common cause of pericardial effusion in developing countries.

- Negative tuberculin skin test or a pericardial fluid PCR for tuberculosis does not exclude tuberculous pericarditis.

- Diagnostic pericardiocentesis should be done for any case of suspected tuberculous pericarditis.

- Lymphocyte predominant pericardial exudate with high adenosine deaminase level suggests tuberculous pericarditis, and response to antituberculous therapy confirms the diagnosis.

- Left recurrent nerve paralysis is due to a lesion along the course of the nerve from the base of the skull till the level of the aortic arch.
Competing interests None.

Patient consent Obtained.

\section{REFERENCES}

1. Sayed F, Mayosi B. A modern approach to tuberculous pericarditis. Progress in cardiovascular diseases. 2007;50:218-36.

2. Ortbals DW, Avioli LV. Tuberculous pericarditis. Arch Intern Med 1979:139:231-4.

3. Cherian G, Habashy AG, Uthaman B, et al. Detection and follow-up of mediastinal lymph node enlargement in tuberculous pericardial effusions using computed tomography. Am J Med 2003;114:319-22.

4. Liu PY, Li YH, Tsai WC, et al. Usefulness of echocardiographic intrapericardial abnormalities in the diagnosis of tuberculous pericardial effusion. Am J Cardiol 2001;87:1133-5.

5. Meral M, Akgun M, Kaynar H, et al. Mediastinal lymphadenopathy due to mycobacterial infection. Jpn J Infect Dis 2004;57:124-6.

This pdf has been created automatically from the final edited text and images.

Copyright 2011 BMJ Publishing Group. All rights reserved. For permission to reuse any of this content visit http://group.bmj.com/group/rights-licensing/permissions.

BMJ Case Report Fellows may re-use this article for personal use and teaching without any further permission.

Please cite this article as follows (you will need to access the article online to obtain the date of publication).

Fouda R, Ammar H, Edward R, Alnabawy WM, Fouda IM. Tuberculous pericarditis associated with hoarseness of voice due to left recurrent laryngeal nerve paralysis. BMJ Case Reports 2011;10.1136/bcr.06.2011.4409, date of publication

Become a Fellow of BMJ Case Reports today and you can:

- Submit as many cases as you like

- Enjoy fast sympathetic peer review and rapid publication of accepted articles

- Access all the published articles

- Re-use any of the published material for personal use and teaching without further permission

For information on Institutional Fellowships contact consortiasales@bmjgroup.com

Visit casereports.bmj.com for more articles like this and to become a Fellow 
BMJ Case Reports 